\title{
Involvement of Stathmin in Proliferation and Differentiation of Immortalized Human Endometrial Stromal Cells
}

\author{
Kazuhiro TAMURA ${ }^{1)}$, Mikihiro YOSHIE ${ }^{1)}$, Takahiko HARA ${ }^{2)}$, Keiichi ISAKA ${ }^{3)}$ and \\ Hiroshi KOGO')
}

1) Department of Endocrine Pharmacology, Tokyo University of Pharmacy and Life Science, 1432-1 Horinouchi, Hachioji 192-0392, 2)Stem Cell Project Group, The Tokyo Metropolitan Institute of Medical Science, 3-18-22 Honkomagome, Tokyo 113-8613 and ${ }^{3)}$ Department of Obstetrics and Gynecology, Tokyo Medical University, 6-7-1 Nishishinjuku, Tokyo 160-

0023, Japan.

\begin{abstract}
Uterine endometrial stromal cells differentiate into decidual cells during the late secretory phase of the menstrual cycle and pregnancy. However, the biochemical mechanisms of decidualization have yet to be definitively elucidated. In the present study, we transfected primary human endometrial stromal cell with a temperature-sensitive mutant of simian virus 40 large $\mathrm{T}$ antigen and thereby established an immortalized stromal cell line (EtsT) in order to examine the role of stathmin, a cytosolic phosphoprotein that regulates microtubule dynamics, in stromal cell differentiation. When treated with the decidual stimulus dibutyryl-cAMP (db-cAMP) or forskolin, the fibroblastic cell-shaped EtsT cells transformed into large- and round-shaped cells and secreted large amounts of the decidual markers prolactin (PRL) and insulin-like growth factor binding protein-1 (IGFBP-1). Analysis of the stathmin protein levels in the db-cAMP- and forskolin-treated EtsT cells revealed that the total and phosphorylated protein levels dropped as decidualization progressed. Suppression of stathmin expression by transfection with small interfering RNA (siRNA) suppressed EtsT cell proliferation. It also abolished db-cAMP-induced PRL and IGFBP-1 mRNA expression and protein secretion. Thus, stathmin expression can be considered an integral factor regulating the initial stage of the process of human endometrial stromal cell differentiation.
\end{abstract}

Key words: A microtubule regulatory protein, Decidualization, Endometrium, Human, Stathmin

(J. Reprod. Dev. 53: 525-533, 2007)

I n humans and ruminants, approximately 10$15 \%$ of all pregnancies end in spontaneous abortion, mostly because of implantation failure [1]. Implantation failure is thought to result from failure of embryos to develop and/or failure of the uterus to prepare itself for pregnancy during the peri-implantation period. In the latter case, stromal cell decidualization is an essential event that prepares the uterus for blastocyst implantation and

Accepted for publication: December 28, 2006

Published online: February 2, 2006

Correspondence: K. Tamura (e-mail: hiro@ps.toyaku.ac.jp) thus the establishment of pregnancy. To date, many factors that are critical for successful implantation have been demonstrated, and the biological activities or functions in the establishment of pregnancy have already been characterized [2,3]. Nevertheless, the precise cellular and molecular mechanisms governing conceptus implantation, uterine decidualization, and placental formation have not been definitively elucidated; this imposes a major limitation on diagnosis and treatment of pregnancy disorders.

Stathmin (Op18) is a ubiquitous cytosolic 
phosphoprotein that has four serine residues at its $\mathrm{N}$-terminus $[4,5]$. Our recent study demonstrated that stathmin is one of several genes whose expression is specifically upregulated in the rat uterus at the site of embryo attachment and at decidual formation during the decidualization process $[6,7]$. This suggests that stathmin may be associated with decidualization of endometrial stromal cells in rodents. Stathmin is also highly expressed in the nervous system and by several cancers, including ovarian and breast cancers [5]. Furthermore, stathmin gene family mRNA levels are particularly high in reproductive tissues, including the uterus in humans [8].

Stathmin functions as a regulator of microtubule (MT) dynamics during cell cycle progression by promoting MT disassembly [10, 11]. It thus increases MT turnover and thereby aids rapid reorganization of the MT cytoskeleton. It also promotes the catastrophes of tubulin by binding to MT plus ends, thereby stimulating the exposed $\beta$ subunit of the terminal tubulin dimers to hydrolyze guanosine 5'-triphosphate (GTP) [11]. Extensive phosphorylation of stathmin by various kinases has been shown to turn off its MT-destabilizing activity, which in turn promotes tubulin polymerization [12, 13].

To date, the differentiation of stromal cells has largely been studied by using primary cultured stromal cells. These types of studies have shown that when uterine endometrial stromal cells transform into decidualized stromal cells, they are altered morphologically and begin to secrete specific decidual proteins [14]. In vitro studies have also shown that stromal cell preparations decidualize when exposed to ovarian steroids (progesterone and estradiol) or agents that activate the cAMP pathway [15]. In our previous report, we also used primary endometrial stromal cell cultures to explore the role of stathmin in decidualization. However, this type of in vitro research is hampered by limitations in the number of primary stromal cells that can be obtained from human patients; more importantly, the differentiation potential of these primary cells is maintained for only a short period. We established an immortalized endometrial stromal cell line to overcome these limitations and employed it to examine the physiological role of stathmin during the in vitro decidualization process.

\section{Materials and Methods}

Tissue collection and immortalization of endometrial stromal cells

Endometrial stromal cells were prepared from the endometrial tissues of patients undergoing surgery or biopsies, as described previously [16]. Sample collection was conducted with the informed consent of the patients in accordance with the requirements of the clinical research ethics committee of the Tokyo Medical University Hospital. Normal tissue samples at the proliferative stage were minced finely with scissors and washed in phosphate buffered saline. The endometrial stromal cells were then isolated as described previously [17]. Briefly, the minced tissue samples were digested in calcium- and magnesium-free Hank's solution (CMF-Hanks) containing 0.25\% collagenase (Type IA; Sigma-Aldrich, St. Louis, MO, USA) and then strained through a $250-\mu \mathrm{m}$ stainless steel sieve (Sanpo, Tokyo, Japan) to remove undigested tissue and mucous material. To remove glandular cells, the filtrates were passed through a $38-\mu \mathrm{m}$ sieve (Sanpo) through which stromal cells can pass. The passed solutions were centrifuged and resuspended in a small volume of CMF-Hanks. These cell preparations were at least 95\% positive for vimentin, and they showed no staining for cytokeratin. For culture, the stromal cells were resuspended in basal medium (DMEM/ F12 without phenol red; Life Technologies, Tokyo, Japan) containing $50 \mathrm{U} / \mathrm{ml}$ penicillin, $50 \mu \mathrm{g} / \mathrm{ml}$ streptomycin, $0.25 \mu \mathrm{g} / \mathrm{ml}$ fungizone (Life Technologies), and 10\% (v/v) charcoal-treated fetal bovine serum (stripped FBS; HyClone, South Logan, UT, USA) and seeded in a tissue culture flask (25 mm², Asahi Techno Glass, Tokyo, Japan). The medium was removed $2 \mathrm{~h}$ later, and the adherent cells were washed with fresh medium and cultured to $40 \%$ confluency for 5 days.

The cells were then infected for $16 \mathrm{~h}$ with retrovirus particles in polybrene that produced a temperature-sensitive form of the simian virus 40 large $\mathrm{T}$ antigen (SV40tsT) and were cultured at the permissive temperature of $32 \mathrm{C}$ until continuously growing cells appeared, as described previously [18]. The retrovirus was produced using PLAT-E retrovirus-packaging cells and the retroviral vector pMESVts, which carries the SV40tsT and neomycin acetyltransferase genes. After removing the medium and washing the cells, culture of the cells 
was continued for about 2 months for cell cloning. Four clones that had high proliferation rates were defined as EtsT endometrial stromal cell lines. One of these lines, denoted as EtsT-ZD1, was used in the present study.

\section{Experimental schedule}

EtsT cells were passaged into 12-well culture plates with basal medium containing 10\% stripped FBS and antibiotics and cultured for about 2 days at $32 \mathrm{C}$ for growth to subconfluency. To induce decidualization, the cells were cultured for 6 days at $39 \mathrm{C}$ in basal medium ( $1 \mathrm{ml} /$ well) containing $2 \%$ stripped FBS and antibiotics supplemented with 1 $\mathrm{mM}$ dibutyryl cyclic AMP (db-cAMP) or $25 \mathrm{mM}$ forskolin. The medium was changed daily and collected 3 and 6 days after decidualization was stimulated. The culture media were examined for the presence of IGF-binding protein-1 (IGFBP-1) and PRL, which are well-known decidual markers. The cultured cells were subjected to immunoblotting (see below) or semi-quantitative RT-PCR analyses (see below). To suppress stathmin expression, the stromal cells were pretreated with stathmin siRNA $24 \mathrm{~h}$ before stimulating decidualization (see below).

Immunoblot analysis of IGFBP-1, PRL, stathmin, and phosphorylated stathmin expression

The cells grown in the culture dishes were lysed using Chaps Cell Extract Buffer (Cell Signaling Technology, Beverly, MA, USA) according to the manufacturer's instructions. The culture medium (10 $\mu \mathrm{g}$ protein) or cell lysate ( $3 \mu \mathrm{g}$ protein) was then subjected to $15-20 \%$ gradient SDS-polyacrylamide gel electrophoresis (PAGE) for analysis of IGFBP-1, PRL, and stathmin expression as described previously [16]. We used a native PAGE system that separates stathmin phosphoisomers according to their charge differences to detect phosphorylated stathmin. After electrotransfer onto polyvinylidene difluoride membranes (Millipore, Bedford, MA, USA), the membranes were blocked with Blocking Buffer (Pierce, Rockford, IL, USA). Immunoblot analysis was performed using an rabbit antiIGFBP-1 antiserum (1:1,000; Upstate Biotechnology, Lake Placid, NY, USA), anti-PRL antibody (1:1000; SAMP\#518, anti-hPRL-IC-5, National Hormone and Peptide Program), anti-stathmin serum (1:10,000; kindly donated by A. Sobel, Institut du Fer a Moulin, Paris, France), and anti-phospho- rylated stathmin antibody $(1: 1,000 ; \mathrm{p}-\mathrm{Op} 18$ : ser16, Santa Cruz Biotechnology, Santa Cruz, CA, USA). The immunoreactive bands were detected by enhanced chemiluminescence (PerkinElmer Life Science, Boston, MA, USA) after incubation with horseradish peroxidase-labeled goat anti-rabbit IgG antibody $(0.5 \mu \mathrm{g} / \mathrm{ml}$, Vector Laboratories, Burlingame, CA, USA). As a loading control, the same membrane was re-probed with anti- $\beta$-actin antibody (1:1,000; Sigma-Aldrich). All blotting experiments were repeated at least three times, and representative data are shown.

\section{RNA isolation and RT-PCR analysis}

Poly $(\mathrm{A})^{+}$RNA was isolated using a QuickPrep Micro mRNA Purification Kit (Amersham Pharmacia Biotech, Buckinghamshire, UK). The poly (A) ${ }^{+}$RNA $(0.25 \mu \mathrm{g})$ was then reversetranscribed and amplified using a One Step RNA PCR Kit (TaKaRa, Ohtsu, Japan) according to the manufacturer's instructions. The sense (S) and antisense (AS) primers used are as follows: $5^{\prime}-$ GTCGCTTGTCTTCTATTCACC-3'(S), 5'-ATGGGG AGAAAGTCAGTTCTC-3' (AS) for stathmin; 5'TGCTGCAGAGGGAGGGAGCCC-3'(S), 5'-AGG GATCCTCCTTCCCATTCCA-3'(AS) for IGFBP-1; 5'-GACAGAGACACCAAGAAGAATCGGAAC ATA-3'(S), 5'-GCAATGGAACGGATCATTAAG GACCTTCTC-3'(AS) for PRL; and 5'-ACCACA GTCCATGCCATCAC-3'(S), 5'-TCCACCACCCTG TTGCTGTA-3' (AS) for glyceraldehyde-3-phosphate dehydrogenase (G3PDH). The G3PDH primers served as an internal control. The PCR protocols used were as follows: 20 cycles of $95 \mathrm{C}$ for $1 \mathrm{~min}, 55$ $\mathrm{C}$ for $45 \mathrm{sec}$, and $72 \mathrm{C}$ for $2 \mathrm{~min}$. The amplified products were separated on $1.5 \%$ agarose gels containing $0.45 \mu \mathrm{g} / \mathrm{ml}$ ethidium bromide.

\section{Treatment with siRNA}

EtsT cells at $60 \%$ confluency were transfected with irreverent control siRNA (50 nM; Santa Cruz Biotechnology) or stathmin siRNA (50 nM; Santa Cruz Biotechnology) for $24 \mathrm{~h}$ according to the manufacturer's instructions. After siRNA treatment, the cells were incubated with or without db-cAMP (1 mM) in basal medium supplemented with $2 \%$ stripped FBS at $37 \mathrm{C}$ for 6 days.

\section{Cell proliferation assay}

To determine the effect of suppression of stathmin on the proliferative capacity of EtsT cells, 
A

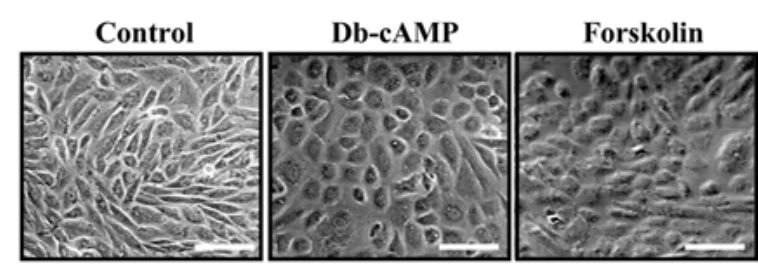

B

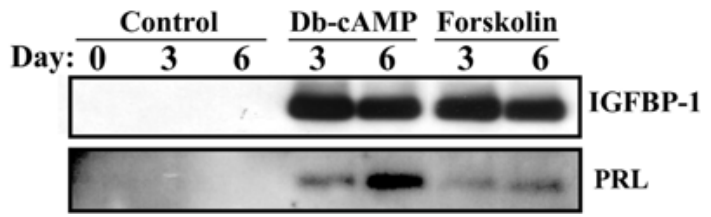

Fig. 1. Effect of decidual stimulation on EtsT cell morphology and IGFBP-1 and prolactin (PRL) secretion. EtsT cells were cultured for 6 days in the presence of $1 \mathrm{mM} \mathrm{db}$ cAMP or $25 \mathrm{mM}$ forskolin. A: Morphology of EtsT cells on day 6 of culture. Photographs were taken under a phase contrast microscope. Bars $=100 \mu \mathrm{m}$. B: Day 0,3 and 6 culture media containing $10 \mu \mathrm{g}$ protein were subjected to immunoblot analysis for IGFBP-1 and PRL. The numbers at the top of Figure 1B indicate the day of culture.

cell proliferation was determined by WST-1 assay (Cell Counting Kit, Dojindo, Kumamoto, Japan). Briefly, EtsT cells $\left(4 \times 10^{4}\right)$ were seeded in 24-well culture plates in DMEM/F12 medium supplemented with $10 \%$ stripped FBS, transfected with siRNA $24 \mathrm{~h}$ later, and cultured for another 24 or 48 $h$. The cells harvested at these time points were incubated with WST-1 reagent for $20 \mathrm{~min}$ at $37 \mathrm{C}$. The staining intensity in the medium was measured by absorbance at $450 \mathrm{~nm}$, and the data were expressed as ratios of the control value.

\section{Statistical analysis}

The cell proliferation rate data were presented as means \pm SEM. Statistical significance $(\mathrm{P}<0.05)$ was determined using the Dunnett test.

\section{Results}

\section{Ability of db-cAMP or forskolin to induce EtsT decidualization}

The immortalized endometrial stromal cells that we established in our laboratory were designated as EtsT cells. After 6 days of culture in culture medium containing $2 \%$ FBS, these cells exhibited a spindle-shaped morphology (Fig. 1A, control), which is similar to primary stromal cells [16]. To determine whether EtsT cells retain the characteristis of primary endometrial stromal cells, we examined their ability to decidualize upon stimulation with forskolin (an activator of protein kinase A) or the cAMP analog db-cAMP. In the presence of either stimulator, the fibroblastic cell-shaped EtsT cells changed morphologically into larger- and roundshaped cells (Fig. 1A, middle and right panels). This morphological change was observed two days after decidual stimulation (data not shown).

To evaluate whether these morphological changes were associated with appropriate functional changes, we examined whether IGFBP-1 and PRL secretion into the culture medium was enhanced. While the unstimulated cells produced barely detectable amounts of IGFBP-1 and PRL throughout days $0-6$, the db-cAMP- and forskolintreated cells clearly secreted more of these markers on days 3 and 6 of culture (Fig. 1B). Notably, the PRL band appeared to be more intense with the $\mathrm{db}$ cAMP treatment than with forskolin and was more intense on day 6 than on day 3 after either decidual stimulation.

\section{Stathmin expression and phosphorylation during EtsT cell decidualization}

We next investigated how the expression of stathmin protein levels changed during EtsT decidualization (Fig. 2). Thus, EtsT cells were treated with db-cAMP or forskolin, and their total stathmin protein (A) and phosphorylated stathmin (B) levels were determined by immunoblot analysis. The total stathmin protein levels of the untreated cells tended to decrease over time, while the stathmin form with three or four phosphorylated sites almost completely disappeared by days 3 and 6 of culture. However, these effects were much more pronounced in the db-cAMP- and forskolinstimulated cells. Indeed, total and phosphorylated stathmin expression had almost completely disappeared in these cells by day 6 of culture.

\section{Effects of stathmin suppression on EtsT cell proliferation}

The effect of stathmin suppression on EtsT proliferation was evaluated using the WST-1 assay (Fig. 3). As expected, the stathmin siRNAtransfected cells had reduced stathmin levels $24 \mathrm{~h}$ 


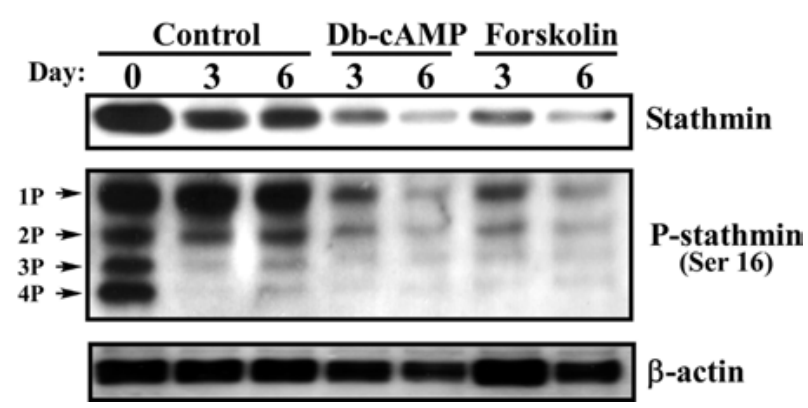

Fig. 2. Stathmin and phosphorylated stathmin levels during forskolin- or db-cAMP-induced EtsT cell decidualization. The cells were cultured for 6 days with $1 \mathrm{mM}$ $\mathrm{db}$-cAMP or $25 \mathrm{mM}$ forskolin with daily media changes. Cell lysates were prepared on days 0,3 and 6 of culture, and lysates containing $3 \mu \mathrm{g}$ protein were separated using SDS polyacrylamide gels (upper panel) or glycerol/urea gels (middle panel) and subjected to immunoblot analysis using a polyclonal anti-stathmin antibody (upper panel) or antiphosphorylated stathmin (Ser-16) antibody (middle panel). The same membrane was re-probed with an anti- $\beta$-actin as a loading control (lower panel).

and $48 \mathrm{~h}$ after transfection (Fig. 3A). Importantly, the cells also had significantly lower proliferation rates $48 \mathrm{~h}$ after siRNA treatment compared with the control cells; smaller reductions in proliferation rates were observed at $24 \mathrm{~h}$ (Fig. 3B).

\section{Effects of stathmin suppression on EtsT decidualization}

To determine the physiological significance of stathmin in in vitro decidualization, we examined the effect of stathmin mRNA suppression on $\mathrm{db}$ cAMP-induced EtsT decidualization (Fig. 4). Thus, EtsT cells were pretreated with stathmin siRNA for $24 \mathrm{~h}$ prior to db-cAMP stimulation. The siRNA treatment markedly decreased stathmin mRNA expression, with minimal expression observed on days 3 and 6 (Fig. 4A); this inhibitory effect lasted until at least day 6 and was similar to what has been observed with stathmin siRNA-treated, freshly prepared primary stromal cells [16]. Significantly, the stathmin siRNA also suppressed db-cAMPstimulated IGFBP-1 and PRL transcription (Fig. 4A). Moreover, immunoblot analysis of the culture media revealed that siRNA treatment markedly inhibited db-cAMP-stimulated secretion of both the IGFBP-1 and PRL proteins (Fig. 4B). The cellular stathmin and IGFBP-1 levels were also markedly

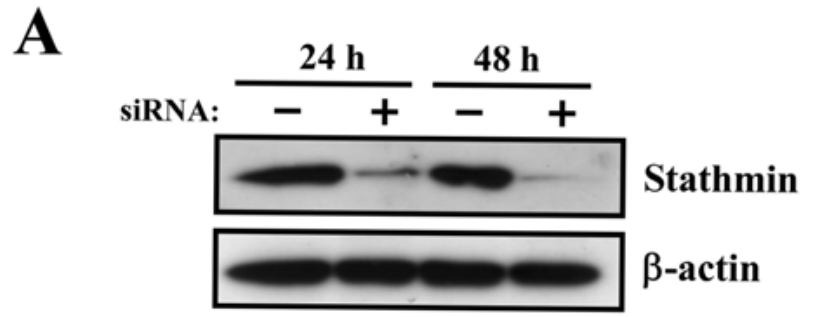

B

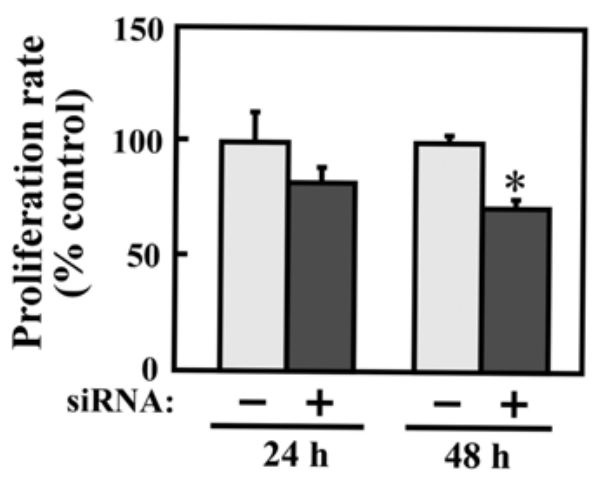

Fig. 3. Effect of stathmin suppression on EtsT cell proliferation. The cells were treated for $24 \mathrm{~h}$ with stathmin siRNA or an irrelevant control siRNA (stathmin siRNA: -) and then further cultured for 24 and $48 \mathrm{~h}$. A: The stathmin levels in the EtsT cells were determined by Western blot analysis to confirm stathmin suppression. The membrane was re-probed with $\beta$-actin as a loading control. B: The proliferation rates of the cells were determined using WST-1 reagent. The data are represented as ratios of the control and are shown are means \pm SEM from three independent experiments. ${ }^{*} \mathrm{P}<0.01$ vs. stathmin siRNA (-).

inhibited by siRNA treatment (data not shown). However, there were no differences in the morphological changes to larger and rounder phenotype cells between the control and stathmin siRNA-treated groups, as shown in Fig. 4C.

\section{Discussion}

In the present study, we established a human EtsT cell line and showed that it has cAMP-sensitive differentiation potential. We demonstrated that siRNA-induced downregulation of stathmin expression decreased the proliferation of EtsT cells. We then showed that suppression of stathmin 

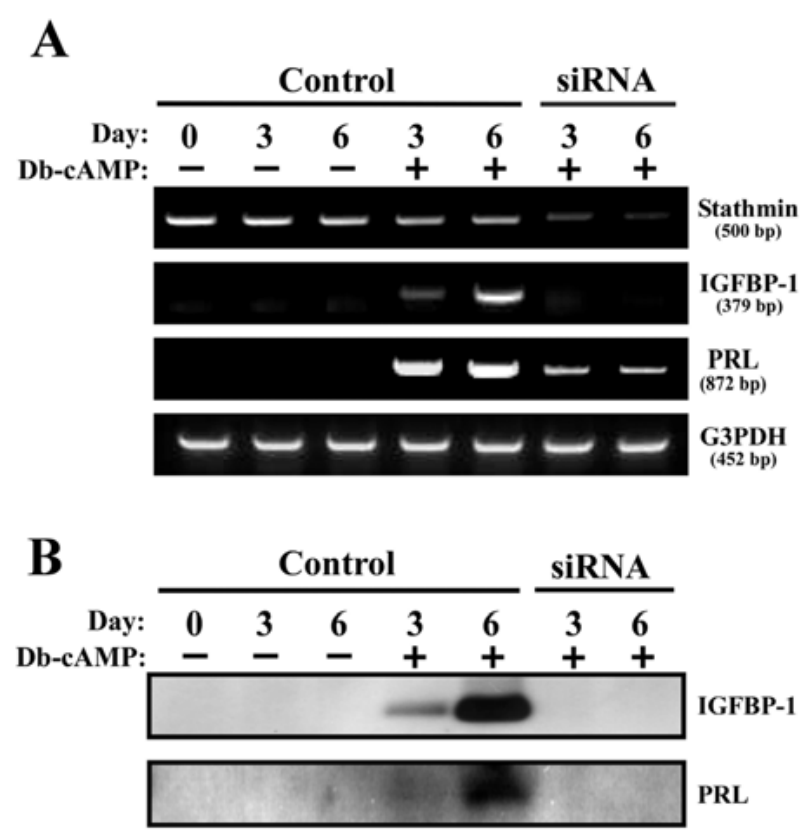

C

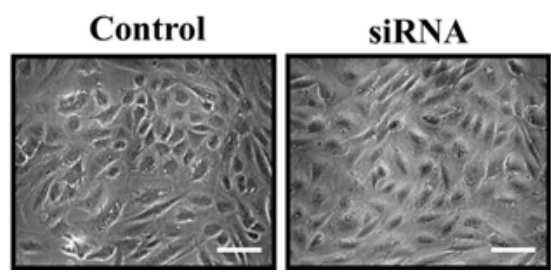

Fig. 4. Effect of stathmin suppression on db-cAMP-induced EtsT cell decidualization. The cells were transfected with stathmin siRNA 24 h before decidual stimulation and then cultured for 6 days in the absence $(-)$ or presence $(+)$ of $1 \mathrm{mM}$ db-cAMP. The culture media and cells were collected on days 0,3 and 6 of culture. A: Total EtsT cell RNA was subjected to RT-PCR analysis for IGFBP-1, PRL and stathmin expression. G3PDH served as an internal control. B: The IGFBP-1 and PRL levels in the culture media were determined by immunoblot analysis. C: Phase contrast microscopy images of control and stathmin siRNA-treated cells. The cells transfected with control siRNA or stathmin siRNA were cultured for 3 days in the presence of $1 \mathrm{mM} \mathrm{db}$-cAMP and then photographed. Bars $=100 \mu \mathrm{m}$.

expression blocked db-cAMP-induced decidualization of the EtsT cells. Thus, our study supports previous observations suggesting that stathmin may be involved in the proliferation and/ or differentiation of primary endometrial cells in humans [16].

Ovarian steroids induce endometrial stromal cell differentiation by activating the cAMP pathways and stromal cells that are freshly isolated from normal endometrial tissues decidualize when treated with either progesterone plus estradiol or $\mathrm{db}$-cAMP [15]. In fact, several endometrial cell lines respond to steroid treatment [20]; however, the EtsT cell line does not decidualize upon treatment with progesterone plus estradiol (data not shown). Similarly, an endometrial cell line established in another laboratory did not respond to progesterone plus estradiol [21]. Thus, it appears that the intracellular signaling system between progesterone receptor (PR) activation and cAMP generation may be impaired in EtsT cells. Furthermore, this line may have lost its functional PR during establishment.

Stathmin expression is upregulated specifically at the site of embryo implantation and in the decidual zone but is downregulated as decidualization progresses in rodents $[6,7]$. In humans, a significant increase in stathmin expression is not observed at the onset of decidualization. EtsT proliferation decreased in this study when endogenous stathmin mRNA expression was suppressed before decidual stimulation. This suggests that stathmin may regulate stromal cell proliferation prior to decidualization. On the other hand, it has been proposed that stathmin may aid by limiting "overproliferation" of cells during the cell cycle prior to cell commitment and/or differentiation [4]. Thus, stathmin probably promotes or maintains proper proliferation and possibly negatively downregulates excessive proliferation. Importantly, our observations of decreased decidual marker (IGFBP-1 and PRL) expressions following stathmin mRNA suppression suggest that stathmin is likely involved in preparation for or initiation of decidualization. Unexpectedly, suppression of stathmin mRNA expression did not affect the morphological changes usually seen after decidual stimulation. This result may indicate that the morphological changes during decidualization processes are not necessarily associated with enhanced secretion of IGFBP-1 and PRL. These results suggest that stathmin is probably involved in changes in secretory function during decidualization.

We also found that decidual stimuli induced the EtsT endometrial stromal cell line to differentiate and that this was associated with a decrease in stathmin expression over time. Moreover, we 
found that EtsT decidualization was associated with acute decreases in the levels of the phosphorylated forms of stathmin. These observations are basically consistent with the changes in stathmin levels detected in primary endometrial stromal cell cultures undergoing decidualization [16]. Thus, it appears that as endometrial stromal cells begin to differentiate, stathmin activity drops. Given that stathmin promotes MT destabilization and is downregulated by its sequential phosphorylation, it is likely that the drop in stathmin activity permits the formation of the MT network and allows the mitotic spindle to form. This is supported by the fact that phosphorylated stathmin levels increase as cells enter the G2/M phase of the cell cycle. Indeed, phosphorylation of stathmin at multiple sites is required for orderly progression of the cell cycle [5]. Thus, both phosphorylation (inactivation) and dephosphorylation (reactivation) of stathmin are essential for cytokinesis and proper progression of the cell cycle. The decrease in both the total and phosphorylated stathmin levels of the stromal cells is consistent with a previous study showing that stathmin is highly expressed in undifferentiated cells but decreased during the induction of cell differentiation $[22,23]$. Thus, it appears that the function of stathmin in decidualization is no longer required as endometrial stromal cells begin to differentiate. Stathmin levels then drop, thereby permitting formation of the MT network and promotion of stromal cell differentiation into decidual cells.

The decidualization of endometrial stromal cells that occurs in the late secretory phase of the menstrual cycle is characterized by morphological and functional changes $[3,24]$ that involve exit from the cell cycle. Thus, regulation of endometrial stathmin expression could be associated with the changes in the cell cycle in the endometrium during the secretory phase. The observation that the promoter region of the stathmin gene contains three E2F-binding sites suggests that stathmin expression and activity are linked to the cell cycle because DNA replication and mitotic activity are regulated through E2F [25]. Since cyclin D promotes E2F-mediated transactivation by releasing active E2F from pRB [26], it is possible that stathmin expression is regulated indirectly by cyclin D3 and p27 $7^{\mathrm{kip} 1}$. Indeed, $\mathrm{p} 27^{\mathrm{kip} 1}$ has been found to impair stathmin function, thereby inhibiting cell motility $[27,28]$. The precise role stathmin plays in decidualization is unclear. However, it is possible that its MT destabilizing activity may facilitate important changes in the cytoskeleton that support subsequent differentiation-related changes in endometrial stromal cells. This is supported by the fact that differentiation of stromal cells is associated with cytoskeletal changes [29]. For example, in the baboon endometrium, the actin cytoskeleton is regulated by interactions between integrins and the extracellular matrix [30]. Moreover, the cytoskeleton of stromal cells is reorganized by the interleukin $1 \beta$ secreted by embryos, which enhances cyclooxygenase and matrix metalloproteinase- 3 activity in stromal cells; these activities dissociate the cytoskeleton, including $\alpha$ smooth muscle actin, and induce decidualization. Furthermore, disruption of the actin filament by cytochalasin D promotes stromal cell decidualization [31]. Significantly, it has recently been shown that both hCG and db-cAMP can prevent stromal cell apoptosis after cytoskeletal disruption in vitro [32]. Thus, decidualization appears to require disruption of the cytoskeleton. While it has not yet been shown whether stathmin expression can regulate actin filament dynamics, it is possible that the MT instability induced by increased stathmin expression facilitates disruption of the cytoskeletal apparatus and thereby promotes stromal cell decidualization.

In conclusion, the clear suppression of decidualization in EtsT cells subjected to suppression of stathmin expression prior to decidual stimulation observed in the present study indicates that stathmin plays a role during the initial stage of endometrial stromal cell decidualization.

\section{Acknowledgments}

The authors gratefully acknowledge Dr. A. Sobel (INSERM U440, Institut du Fer a Moulin, Paris, France) and Dr. A.F. Parlow (Pituitary Hormone and Antisera Center) for providing the antistathmin antiserum and anti-human prolactin antibody, respectively. This work was partially supported by a Grant-in-Aid for Scientific Research (16591689) to K. T. from the Japan Society for the Promotion of Science. 


\section{References}

1. Wilcox AJ, Baird DD, Weinberg CR. Time of implantation of the conceptus and loss of pregnancy. J Neurochem 1989; 53: 53856-53863.

2. Cross JC, Werb Z, Fisher SJ. Implantation and the placenta: key pieces of the development puzzle. Science 1994; 266: 1508-1518.

3. Dey SK, Lim H, Das SK, Reese J, Paria BC, Daikoku T, Wang H. Molecular cues to implantation. Endocr Rev 2004; 25: 341-373.

4. Curmi PA, Gavet O, Charbaut E, Ozon S, LachkarColmerauer S, Manceau V, Siavoshian S, Maucuer A, Sobel A. Stathmin and its phosphoprotein family: general properties, biochemical and functional interaction with tubulin. Cell Struct Funct 1999; 24: 345-357.

5. Rubin CI, Atweh GF. The role of stathmin in the regulation of the cell cycle. J Cell Biochem 2004; 93: 242-250.

6. Tamura K, Hara T, Yoshie M, Irie S, Sobel A, Kogo H. Enhanced expression of uterine stathmin during the process of implantation and decidualization in rats. Endocrinology 2003; 144: 1464-1473.

7. Yoshie $\mathbf{M}$, Tamura $\mathbf{K}, \mathbf{K o g o} \mathbf{H}$. Differential localization of decidual stathmin during pregnancy in rats. Placenta 2004; 25: 449-455.

8. Bieche I, Maucuer A, Laurendeau I, Lachkar S, Spano AJ, Frankfurter A, Levy P, Manceau V, Sobel A, Vidaud M, Curmi PA. Expression of stathmin family genes in human tissues: nonneural-restricted expression for SCLIP. Genomics 2003; 81: 400-410.

9. Rowlands DC, Williams A, Jones NA, Guest SS, Reynolds GM, Barber PC, Brown G. Stathmin expression is a feature of proliferating cells of most, if not all, cell lineages. Lab Invest 1995; 72: 100-113.

10. Belmont LD, Mitchison TJ. Identification of a protein that interacts with tubulin dimers and increases the catastrophe rate of microtubules. Cell 1996; 84: 623-631.

11. Nogales E, Wang HW, Niederstrasser H. Tubulin rings: which way do they curve? Curr Opin Struct Biol 2003; 13: 256-261.

12. Gavet O, Ozon S, Manceau V, Lawler S, Curmi P, Sobel A. The stathmin phosphoprotein family: intracellular localization and effects on the microtubule network. J Cell Sci 1998; 111: 3333-3346.

13. Gradin HM, Larsson N, Marklund U, Gullberg M. Regulation of microtubule dynamics by extracellular signals: cAMP-dependent protein kinase switches off the activity of oncoprotein 18 in intact cells. J Cell Biol 1998; 140: 131-141.

14. Tabanelli S, Tsang B, Gurpide E. In vitro decidualization of human endometrial stromal cells. J Steroid Biochem Mol Biol 1992; 42: 337-344.

15. Telgmann $\mathbf{R}$, Gellersen B. Marker genes of decidualization: activation of the decidual prolactin gene. Hum Reprod Update 1998; 4: 472-479.

16. Tamura K, Yoshie M, Nishi H, Osakabe Y, Isaka K, Hara T, Kogo H. Expression of stathmin in human uterus and decidualizing endometrial stromal cells. Reproduction 2006; 132: 625-636.

17. Satyaswaroop PG, Bressler RS, de la Pena MM, Gurpide E. Isolation and culture of human endometrial glands. J Clin Endocrinol Metab 1979; 48: 639-641.

18. Nakayama $Y$, Nara N, Kawakita $Y$, Takeshima $Y$, Arakawa M, Katoh M, Morita S, Iwatsuki K, Tanaka K, Okamoto S, Kitamura T, Seki N, Matsuda R, Matsuo M, Saito K, Hara T. Cloning of cDNA encoding a regeneration-associated muscle protease whose expression is attenuated in cell lines derived from Duchenne muscular dystrophy patients. Am J Pathol 2004; 164: 1773-1782.

19. Barbier CS, Becker KA, Troester MA, Kaufman DG. Expression of exogenous human telomerase in cultures of endometrial stromal cells does not alter their hormone responsiveness. Biol Reprod 2005; 73: 106-114.

20. Krikun G, Mor G, Alvero A, Guller S, Schatz F, Sapi E, Rahman $M$, Caze $R$, Qumsiyeh $M$, Lockwood CJ. A novel immortalized human endometrial stromal cell line with normal progestational response. Endocrinology 2004; 145: 2291-2296.

21. Brosens JJ, Takeda $\mathrm{S}$, Acevedo $\mathrm{CH}$, Lewis MP, Kirby PL, Symes EK, Krausz T, Purohit A, Gellersen B, White JO. Human endometrial fibroblasts immortalized by simian virus 40 large $\mathrm{T}$ antigen differentiate in response to a decidualization stimulus. Endocrinology 2000; 137: 2225-2231.

22. Schubart UK, Xu J, Fan W, Cheng G, Goldstein H, Alpini G, Shafritz DA, Amat JA, Farooq M, Norton WT, et al. Widespread differentiation stage-specific expression of the gene encoding phosphoprotein p19 (metablastin) in mammalian cells. Differentiation 1992; 51: 21-32.

23. Liu A, Stadelmann C, Moscarello M, Sobel A, Mastronardi FG, Casaccia Bonnefil P. Expression of stathmin, a developmentally controlled cytoskeletonregulating molecule, in demyelinating disorders. $J$ Neurosci 2005; 25: 737-747.

24. Strauss III JF, Lessey BA. The structure, function, and evaluation of the female reproductive tract. In: Strauss III JF, Barbieri RL (eds.), Yen and Jaffe's Reproductive Endocrinology (Physiology, Pathophysiology, and Clinical Management), 5th ed: Elsevier Saunders Inc; 2004: 225-305.

25. Ishida S, Huang E, Zuzan H, Spang R, Leone G, West M, Nevins JR. Role for E2F in control of both 
DNA replication and mitotic functions as revealed from DNA microarray analysis. Mol Cell Biol 2001; 21: 4684-4699.

26. Bartek J, Bartkova J, Lukas J. The retinoblastoma protein pathway and the restriction point. Curr Opin Cell Biol 1996; 8: 805-814.

27. Baldassarre G, Belletti B, Nicoloso MS, Schiappacassi $M$, Vecchione A, Spessotto $P$, Morrione A, Canzonieri V, Colombatti A. p27(Kip1)-stathmin interaction influences sarcoma cell migration and invasion. Cancer Cell 2005; 7: 5163.

28. Rubin CI, Atweh GF. p27Kip1 and stathmin share the stage for the first time. Trends Cell Biol 2005; 15: 346348.

29. Fazleabas AT, Kim JJ, Strakova Z. Implantation: Embryonic signals and the modulation of the uterine environment-A review. Placenta 2004; 25: (Suppl A): S26-S31.

30. Fazleabas AT, Bell SC, Fleming S, Sun J, Lessey BA. Distribution of integrins and the extracellular matrix proteins in the baboon endometrium during the menstrual cycle and early pregnancy. Biol Reprod 1997; 56: 348-356.

31. Kim JJ, Jaffe RC, Fazleabas AT. Insulin-like growth factor binding protein-1 expression in baboon endometrial stromal cells: regulation by filamentous actin and requirement for de novo protein synthesis. Endocrinology 1999; 140: 997-1004.

32. Jasinska A, Strakova Z, Szmidt M, Fazleabas AT. Human chorionic gonadotropin and decidualization in vitro inhibits cytochalasin-D-induced apoptosis in cultured endometrial stromal fibroblasts. Endocrinology 2006; 147: 4112-4121. 